Check for updates

Cite this: New J. Chem., 2018, 42,8596

Received 15th March 2018, Accepted 12th April 2018

DOI: 10.1039/c8nj01277f

rsc.li/njc

\section{Cinchona derivatives as sustainable and recyclable homogeneous organocatalysts for aza-Markovnikov addition $\dagger$}

\author{
Sándor Nagy, (D) Zsuzsanna Fehér, Péter Kisszékelyi, (D) Péter Huszthy (D) and \\ József Kupai (D) *
}

\begin{abstract}
Three cinchona derivatives have shown remarkable activity to catalyze the aza-Markovnikov addition reaction of $\mathrm{N}$-heterocycles to vinyl esters. The synthesis of aza-Markovnikov adducts possessing valuable biological activity was thoroughly optimized. By studying the ratio of the starting materials, bases and solvents, we achieved a new and efficient protocol, which could be performed under mild conditions with a small excess of vinyl ester affording products with excellent yields and high regioselectivity. This optimization reduced Sheldon's $E$-factor of the reaction by $42 \%$. Furthermore, membrane separation for catalyst recycling was assessed to further improve the sustainability of the synthesis.
\end{abstract}

\section{Introduction}

Catalytic transformations play an increasingly important role in organic chemistry today, both in academic laboratories and in industries. Organocatalysts, enzymes and homogeneous metal catalysts are expensive, therefore new strategies have to be developed to obtain maximum catalyst performance with regards to selectivity and turnover numbers. Membrane separation in organic media is a sustainable separation technology to achieve these goals, along with process intensification and a cleaner product stream.

Cinchona alkaloids, originally isolated from the bark of Cinchona trees, are amongst the most well-known natural products with exceptional medical history and their derivatives have emerged as powerful organocatalysts, which are reported in several reviews ${ }^{1-4}$ and recently in books. ${ }^{5,6}$ The widespread usage of cinchona alkaloids has been attributed to their nontoxicity, ease of use, stability, cost effectiveness, recyclability, and practical utilization in industries. ${ }^{7-10}$

Aza-Markovnikov addition is a useful nitrogen-carbon bondforming reaction, in particular, for the synthesis of bioactive $\mathrm{N}$-heterocycle derivatives. 1-(N-Heterocycle) alkyl esters, which could be obtained by this reaction, possess valuable biological properties $^{11}$ and can act as acaricides (A), ${ }^{12,13}$ antitumor drugs (B), ${ }^{14}\left(\mathrm{H}^{+}-\mathrm{K}^{+}\right)$-ATPase inhibitors $(\mathrm{C})^{15}$ and are also used to treat

Department of Organic Chemistry and Technology, Budapest University of Technology and Economics, P.O. Box 91, Budapest, H-1521, Hungary.

E-mail: jkupai@mail.bme.hu; Tel: 0036-1463-2229

$\dagger$ Electronic supplementary information (ESI) available: R, NMR and MS data for compounds 13-19. See DOI: 10.1039/c8nj01277f
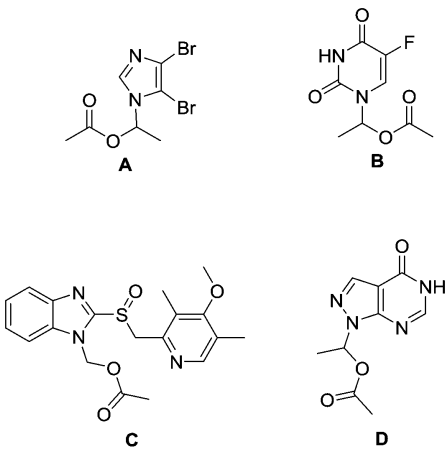

Fig. 1 Biologically active 1-(N-heterocycle) alkyl esters

gout and certain types of kidney stones (D) (see Fig. 1). ${ }^{16}$ Consequently, many researchers have focused on developing new methodologies for the synthesis of 1-(N-heterocycle) alkyl esters. However, most of the reported synthetic protocols are associated with the use of harsh chemical conditions, in which, bases, acids and intense heating are usually applied to promote the reaction. In many cases, yield and selectivity are far from satisfactory due to several side reactions.

Many efforts have been made regarding green syntheses. In the mid-2000s, a new enzymatic strategy to perform Markovnikov addition was developed with the use of penicillin $\mathrm{G}$ acylase as catalyst. ${ }^{16,17}$ Later, Lin and his co-workers applied $\mathrm{K}_{3} \mathrm{PO}_{4}$ as a mild base, ${ }^{11}$ and recently Chen and his co-workers used ionic liquids as reaction media and catalysts. ${ }^{18}$ However, it is unsustainable to scale up this modified synthesis due to the high excess of vinyl ester and the application of problematic solvents such as DMF. 
A serious practical problem with homogeneous catalysis is the separation of reactants and products from the catalyst, which are all in the same phase. The applicability of membrane-based separation for the recovery of homogeneous organocatalysts was explored. Membrane-based separation in organic media is a green technology that allows size-exclusion based separation of solutes in the range of 50 and $2000 \mathrm{~g} \mathrm{~mol}^{-1}$ by applying a pressure gradient. ${ }^{19}$ Recent development in this field resulted in membranes, which can withstand aggressive solvents and exhibit high flux, while quasi completely rejecting relatively small solutes at the lower end of the nanofiltration range. ${ }^{20,21}$ Homogeneous catalyst recovery using membranes is an emerging field due to its mild operating conditions, low cost and easy implementation in continuous processing..$^{22,23}$

Here, we report a new application of cinchona alkaloids in the catalysis of aza-Markovnikov addition. The addition of $\mathrm{N}$-heterocycles (imidazole, benzimidazole, pyrazole or 1,2,3-triazole) to vinyl esters (vinyl acetate or vinyl 4-tert-butylbenzoate) was studied and a mechanism is suggested. Our aim was to develop a new method for efficient synthesis of biologically active azaMarkovnikov adducts, avoiding tedious and expensive repeated purifications and using homogeneous catalysts, which could be easily recycled after the reaction. Furthermore, our new synthesis of aza-Markovnikov adducts was evaluated through Sheldon's $E$-factor. ${ }^{24,25}$

\section{Results and discussion}

To turn the aza-Markovnikov reaction more eco-friendly, two model reactions were chosen (Scheme 1) using N-heterocycles (1 and 2) as substrates and vinyl acetate (3) as a reagent resulting in two aza-Markovnikov adducts (4 and 5).

At first, it was observed that decreasing the reaction temperature (from $50{ }^{\circ} \mathrm{C}$ to $25{ }^{\circ} \mathrm{C}$ ) had no significant effect on the yield of the reaction, (see Table 1, entries 1, 2 and 8, 9) and azaMarkovnikov addition could proceed at room temperature. Then, the influence of solvent, the molar ratio of vinyl acetate and catalyst $\left(\mathrm{K}_{3} \mathrm{PO}_{4}\right)$ to N-heterocycles was investigated. DMF was replaced by a greener alternative, ${ }^{26-28}$ acetonitrile (see Table 1 ), providing an easier work-up process due to its lower boiling point. According to the recent critical review by Byrne et al. ${ }^{29}$ on solvent selection, substitution of DMF is required, and acetonitrile is a suitable replacement. The amounts of catalyst and reagent were also decreased (see Table 1).

The optimized process was compared to previous references by means of Sheldon's $E$-factor. The optimization was carried

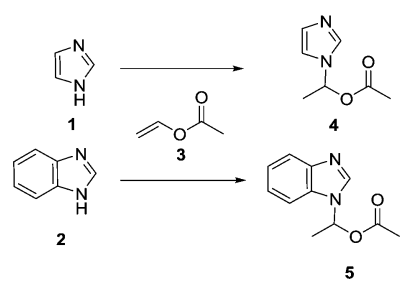

Scheme 1 Two model reactions for optimizing the aza-Markovnikov reaction.
Table 1 Effect of solvent and reaction conditions on the aza-Markovnikov addition reaction of $\mathrm{N}$-heterocycle $\mathbf{1}$ or $\mathbf{2}$ and vinyl acetate $\mathbf{3}$ with catalyst $\mathrm{K}_{3} \mathrm{PO}_{4}{ }^{a, b}$

\begin{tabular}{|c|c|c|c|c|c|c|}
\hline Entry & Reagent & Solvent & $\begin{array}{l}\text { Temperature } \\
{\left[{ }^{\circ} \mathrm{C}\right]}\end{array}$ & $\begin{array}{l}\text { Equivalent } \\
\text { of catalyst }\end{array}$ & $\begin{array}{l}\text { Equivalent } \\
\text { of vinyl ester }\end{array}$ & $\begin{array}{l}\text { Yield }^{b} \\
{[\%]}\end{array}$ \\
\hline 1 & 1 & DMF & 50 & 0.3 & 8 & 65 \\
\hline 2 & 1 & DMF & 25 & 0.3 & 8 & 63 \\
\hline 3 & 1 & DMF & 25 & 0.05 & 8 & 62 \\
\hline 4 & 1 & DMF & 25 & 0.05 & 1.2 & 52 \\
\hline 5 & 1 & MeCN & 25 & 0.3 & 8 & 63 \\
\hline 6 & 1 & MeCN & 25 & 0.05 & 8 & 58 \\
\hline 7 & 1 & MeCN & 25 & 0.05 & 1.2 & 48 \\
\hline 8 & 2 & DMF & 50 & 0.3 & 8 & 61 \\
\hline 9 & 2 & DMF & 25 & 0.3 & 8 & 57 \\
\hline 10 & 2 & DMF & 25 & 0.05 & 8 & 55 \\
\hline 11 & 2 & DMF & 25 & 0.05 & 1.2 & 50 \\
\hline 12 & 2 & $\mathrm{MeCN}$ & 25 & 0.3 & 8 & 60 \\
\hline 13 & 2 & MeCN & 25 & 0.05 & 8 & 55 \\
\hline 14 & 2 & $\mathrm{MeCN}$ & 25 & 0.05 & 1.2 & 44 \\
\hline
\end{tabular}

${ }^{a}$ The aza-Markovnikov addition reaction of N-heterocycle 1 or 2 $(0.6 \mathrm{mmol})$ and vinyl acetate 3 , with the catalyst $\mathrm{K}_{3} \mathrm{PO}_{4}$ in $1.2 \mathrm{~mL}$ of solvent after $48 \mathrm{~h} .{ }^{b}$ Isolated yield of the purified material.

Table 2 Effect of different methods on Sheldon's $E$-factor of the azaMarkovnikov addition reaction of $\mathrm{N}$-heterocycle $\mathbf{1}$ or $\mathbf{2}$ and vinyl acetate $\mathbf{3}$

\begin{tabular}{llll}
\hline Entry & Reagent & $E$-factor $^{a}$ & Ref. \\
\hline 1 & 1 & 2.51 & 11 \\
2 & 1 & 3.05 & 30 \\
3 & 1 & 1.46 & Our work \\
4 & 2 & 2.26 & 11 \\
5 & 2 & 2.52 & 30 \\
6 & 2 & 1.58 & Our work
\end{tabular}

${ }^{a}$ To achieve meaningful comparisons of different processes, solvent is generally excluded from the $E$-factor calculation. It is not possible to include the materials used for chromatographic purification in this comparison, since amounts of these materials are never reported in journal articles.

out considering the load of all input materials. The results are summarized in Table 2, and the $E$-factor for each process is expressed as the mass ratio of waste to the desired aza-Markovnikov adduct.

As a result of the optimization, the yields were a bit lower (in the case of imidazole: from $65 \%$ to $48 \%$, and in the case of benzimidazole: from $61 \%$ to $44 \%$ ). As a positive result, the decreases of $E$-factor calculated over the aza-Markovnikov addition to imidazole and benzimidazole are $42 \%$ and $30 \%$, respectively. Therefore our results suggest that this method is greener than the ones previously reported. ${ }^{11,30}$

Three cinchona catalysts (6-8, see Fig. 2) were also applied as homogeneous catalysts in aza-Markovnikov additions of these $\mathrm{N}$-heterocycles to vinyl esters. Hydroquinine (6) is a commercially
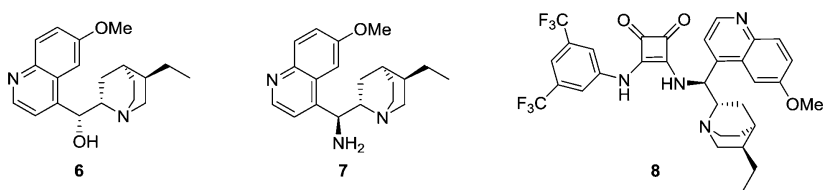

Fig. 2 Schematics of the applied cinchona organocatalysts 6-8. 
available versatile organocatalyst. The latter was converted into its amine derivative (7) after mesylation, azide formation and catalytic hydrogenation. Amine 7 was reacted with the condensation product of 3,5-bis(trifluoromethyl)aniline and dimethyl squarate to give a bifunctional cinchona-squaramide catalyst $8 .^{31}$

Cinchona alkaloids are well-known asymmetric catalysts that give products with high enantiomeric excesses. In the beginning of our study, we tried to prepare aza-Markovnikov adducts enantioselectively. According to our latest experiments, enantiomeric excess is higher when reactions are performed at lower temperatures. Therefore, the cinchona-based organocatalysts were tested and compared to potassium phosphate first at $0{ }^{\circ} \mathrm{C}$ under the previously optimized circumstances in the aza-Markovnikov addition of four different $\mathrm{N}$-heterocycles $(\mathbf{1}, \mathbf{2}, \mathbf{9}, \mathbf{1 0}$, see Table 3) to vinyl acetate (3) or vinyl 4-tert-butylbenzoate (11). Mostly, the yields were lower when cinchona catalysts were used instead of potassium phosphate and the reactions gave racemic (ee lower than $5 \%$ ) products $(4,5,12-19$, see Table 3 ).

The results suggest that the acyloyl part of the reagent has no influence on the reactivity: there was no significant difference between the aliphatic and aromatic reagents. By using cinchona catalysts 6-8, we achieved better yields only in the case of reactions with imidazole (1) and benzimidazole (2). Hence, we continued the optimization using $\mathrm{N}$-heterocycles $\mathbf{1}$ and $\mathbf{2}$ and vinyl acetate (3) at elevated temperatures to produce aza-Markovnikov adducts $\mathbf{4}$ and $\mathbf{5}$ with higher yields.

Finally, cinchona-based organocatalysts 6-8 were applied at $25{ }^{\circ} \mathrm{C}$ and $50{ }^{\circ} \mathrm{C}$, and the results were compared to those obtained using potassium phosphate. As shown in the results in Table 4, by applying cinchona amine 7 , we obtained the aza-Markovnikov adducts with two times higher yields, than in the case when potassium phosphate was used. Consequently, based on our experimental results, the aza-Markovnikov reaction can be performed most environmentally friendly at $25{ }^{\circ} \mathrm{C}$, using acetonitrile as a solvent and $5 \mathrm{~mol} \%$ of cinchona amine 7 . The high yield obtained by using cinchona amine 7 , can be attributed to mechanistic reasons. The above experimental results, in accordance with the literature, ${ }^{32}$ suggest a mechanism for the aza-Markovnikov addition reaction catalyzed by cinchona amine 7 as shown in Scheme 2. In a similar manner to aminocatalysis, ${ }^{33}$ first the quinuclidine nitrogen of the cinchona amine 7 deprotonates the imidazole, then the primary amino group of the cinchona amine 7 forms an enaminetype intermediate with vinyl acetate (3). After that, the non-bonding electron pair of the deprotonated imidazole attacks the electron poor carbon atom of vinyl acetate (3). Finally, with the elimination of the product (4), the starting cinchona amine 7 is recovered.

Organic solvent nanofiltration (OSN) for recycling the cinchona catalysts 6-8 was explored. Commercial GMT-oNF and in-house fabricated PBI (poly[2,2'-( $m$-phenylene)-5, $5^{\prime}$-bisbenzimidazole $]$ ) membranes were screened in acetonitrile at 10-30 bar pressure to determine their separation potential (Fig. 3). Efficient catalyst recovery requires as high catalyst rejection as possible, ideally $100 \%$. The GMT-oNF-3 and PBI membranes at 30 bar showed the highest catalyst rejection of $98.3 \%$ and $99.1 \%$, respectively. The latter membrane was selected for the purification process because of the lower product rejection (17\%) compared to that
Table 3 Catalytic aza-Markovnikov addition reaction of various N-heterocycles ( $\mathbf{1}$ or $\mathbf{2}$ or $\mathbf{9}$ or $\mathbf{1 0}$ ) and vinyl esters ( $\mathbf{3}$ or $\mathbf{1 1}$ ) under the optimized conditions $s^{a, b, c, d}$
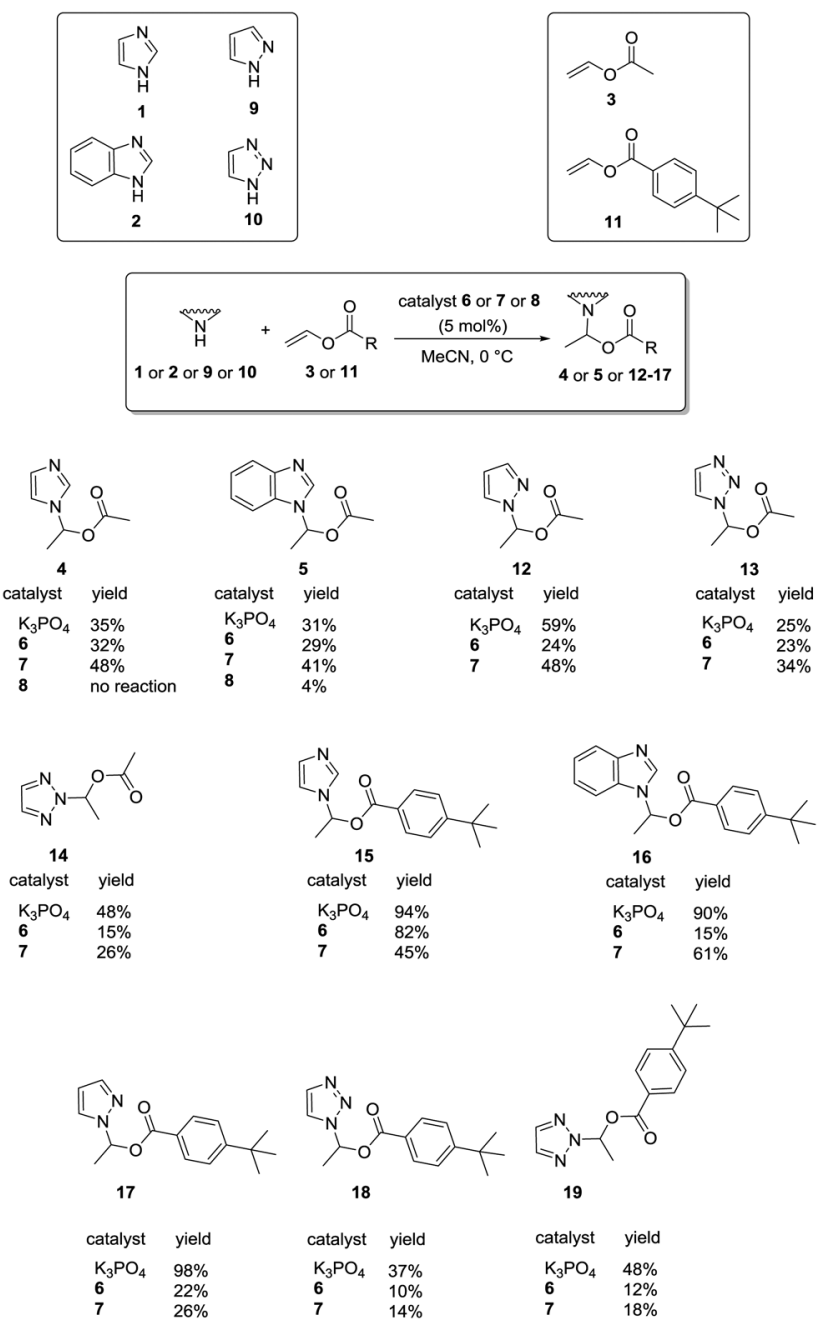

${ }^{a}$ The aza-Markovnikov addition reaction of various N-heterocycles 1 or 2 or 9 or $10(0.6 \mathrm{mmol})$ and vinyl esters 3 or $11(0.72 \mathrm{mmol}, 1.2 \mathrm{eq}$. $)$, with catalysts $\mathrm{K}_{3} \mathrm{PO}_{4}$ or 6 or 7 or 8 , in $1.2 \mathrm{~mL}$ of acetonitrile at $0{ }^{\circ} \mathrm{C}$. ${ }^{b}$ Isolated yield of the purified material. ${ }^{c}$ After unsuccessful results were observed in the case of products 4 and $\mathbf{5}$, catalyst $\mathbf{8}$ was not applied in the other reactions. ${ }^{d}$ Starting from vinyl acetate (3) or vinyl 4-tert-butylbenzoate (11), and 1,2,3-triazole (10) two products (13 and 14) or (16 and 17) formed in about a $1: 1$ ratio.

Table 4 Catalytic aza-Markovnikov addition reaction of $\mathrm{N}$-heterocycles (1 or 2) and vinyl acetate (3) at different temperatures ${ }^{a}$

\begin{tabular}{|c|c|c|c|c|c|c|c|c|c|}
\hline \multirow{2}{*}{$\begin{array}{l}\text { Yields (\%) } \\
\text { of } 4 \text { at: }\end{array}$} & \multicolumn{4}{|c|}{ Catalyst } & \multirow{2}{*}{$\begin{array}{l}\text { Yields (\%) } \\
\text { of } 5 \text { at: }\end{array}$} & \multicolumn{4}{|c|}{ Catalyst } \\
\hline & $\mathrm{K}_{3} \mathrm{PO}_{4}$ & 6 & 7 & 8 & & $\mathrm{~K}_{3} \mathrm{PO}_{4}$ & 6 & 7 & 8 \\
\hline $0{ }^{\circ} \mathrm{C}$ & 35 & 32 & 48 & 0 & $0{ }^{\circ} \mathrm{C}$ & 31 & 29 & 41 & 4 \\
\hline $25{ }^{\circ} \mathrm{C}$ & 48 & 35 & 95 & 0 & $25{ }^{\circ} \mathrm{C}$ & 44 & 39 & 92 & 4 \\
\hline $50^{\circ} \mathrm{C}$ & 91 & 57 & 98 & 77 & $50{ }^{\circ} \mathrm{C}$ & 89 & 60 & 96 & 74 \\
\hline
\end{tabular}

${ }^{a}$ The aza-Markovnikov addition reaction of N-heterocycles 1 or $2(0.6 \mathrm{mmol})$ and vinyl acetate 3 , with catalysts $\mathrm{K}_{3} \mathrm{PO}_{4}$ or cinchona catalysts 6-8 in $1.2 \mathrm{~mL}$ of acetonitrile at different temperatures for $48 \mathrm{~h}$.

of GMT-oNF-3. The rejection of vinyl acetate (3), resulting from the 0.2 molar excess, was found to be as low as $13 \%$, which allows rapid purge from the system. 


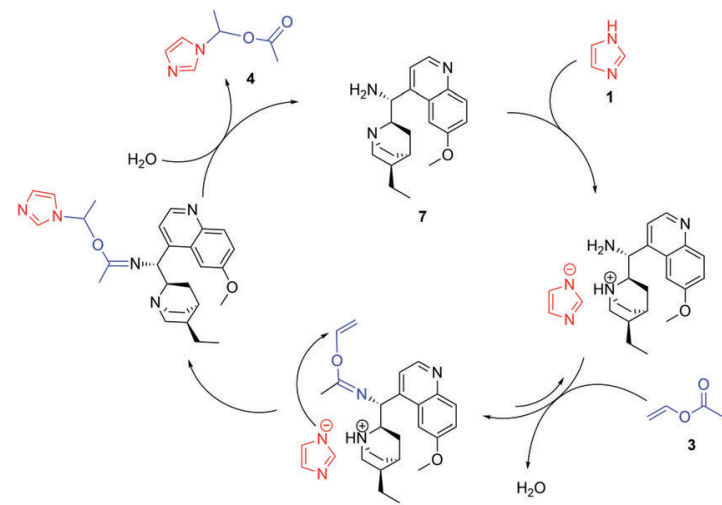

Scheme 2 Suggested mechanism for the aza-Markovnikov reaction using cinchona amine $\mathbf{7}$ as a catalyst.

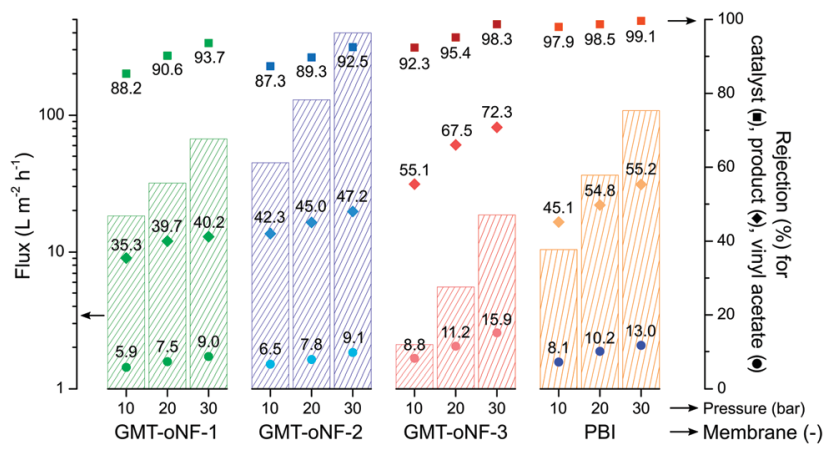

Fig. 3 Separation performance of the nanofiltration membranes in acetonitrile at $10-30$ bar pressure.

The single stage diafiltration allowed $99 \%$ product removal in 8.7 diavolumes at the cost of $8 \%$ catalyst lost (Fig. 4). The simplified membrane cascade developed by Kim et al. offers a

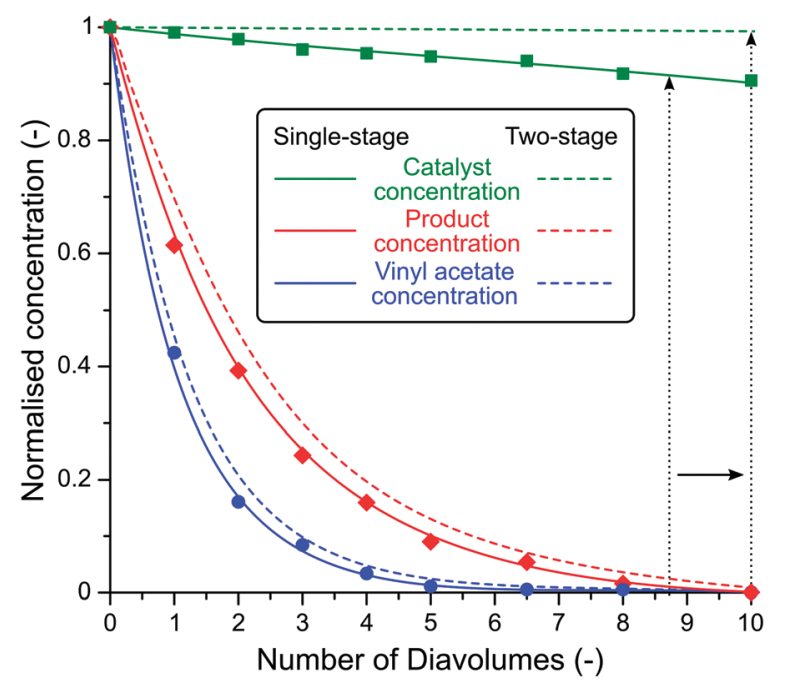

Fig. 4 Purification performance of single-stage and two-stage diafiltration processes using a PBI membrane in acetonitrile. Solid and dashed lines represent the simulated performance based on rejections, while symbols signify the experimental points to validate the model used for the simulation. Dotted lines indicate $99 \%$ product removal from the system, which requires about 8.7 and 10 diavolumes for single-stage and two-stage diafiltration, respectively. sustainable approach to improve the catalyst recovery. ${ }^{34}$ Application of their process configuration resulted in a twostage diafiltration cascade that requires about 10 diavolumes to achieve $99 \%$ product removal and at the same time the catalyst loss can be maintained as low as $1 \%$ (Fig. 4). The purity of the recycled cinchona catalyst 7 was confirmed by NMR, which confirmed that these catalysts do not degrade under the mild conditions applied during these reactions. The sustainability of the diafiltration can be further improved by in situ solvent recovery as recently demonstrated by Szekely et al. ${ }^{35,36}$

\section{Conclusions}

In summary, a series of reported $(4,5,12)$ and novel (13-19) 1-(N-heterocycle) alkyl esters were synthesized and characterized. Aza-Markovnikov reactions were performed environmentally friendly at room temperature, by replacing undesirable dimethyl formamide with acetonitrile, and decreasing the amount of the catalyst (from $30 \%$ to $5 \%$ ) and vinyl ester (from 8 equivalent to 1.2 equivalent). The Sheldon's $E$-factors calculated for the aza-Markovnikov addition to imidazole and benzimidazole were reduced by $42 \%$, and $30 \%$, respectively.

Cinchona-based organocatalysts were synthesized and successfully applied in aza-Markovnikov addition as homogeneous catalysts. Using cinchona amine 7 as a catalyst, we obtained more than twice as high yield (92-95\%) as that obtained using potassium phosphate. In the former case, a reaction mechanism was suggested.

The homogeneous catalytic implementation of aza-Markovnikov addition made this reaction more environmentally friendly by using OSN as its work up process. Due to the OSN technique, the applied catalysts were quasi completely recycled from the reaction mixture. The feasibility of membrane-based separation for catalyst recovery was demonstrated with potential to keep the catalyst loss below $1 \%$ using a two-stage cascade configuration.

\section{Experimental - materials}

GMT-ONF-1, GMT-oNF-2 and GMT-oNF-3 membranes were purchased from BORSIG Membrane Technology GmbH (Germany). $26 \mathrm{wt} \%$ polybenzimidazole dissolved in $N, N$-dimethylacetamide (DMAc) was purchased from PBI Performance Products Inc. (USA). Non-woven polypropylene fabric Novatexx 2471 was obtained from Freudenberg Filtration Technologies (Germany).

\section{Experimental - membrane screening and diafiltration}

The polybenzimidazole (PBI) membrane was prepared from a $26 \mathrm{wt} \%$ dope solution on a non-woven support sheet using a casting knife set to a thickness of $100 \mu \mathrm{m}$ at a temperature of $20{ }^{\circ} \mathrm{C}$ based on the literature procedure. ${ }^{37}$ The feed solution for the membrane screening comprised a mixture of catalyst, product, and substrate each of them in $0.1 \mathrm{~g} \mathrm{~L}^{-1}$ concentration in acetonitrile. The pressure range for the screening was 10-30 bar 


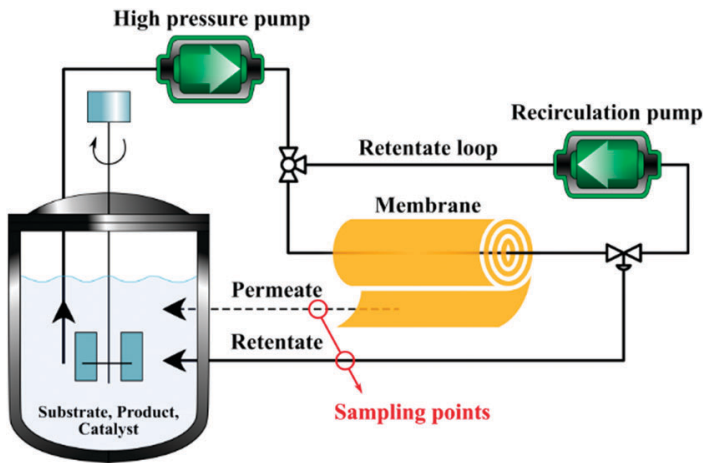

Fig. 5 Schematic representation of the experimental set-up of cross-flow membrane filtration.

and the tests were carried out in a cross-flow nanofiltration rig (Fig. 5). The feed solution was recirculated for $24 \mathrm{~h}$ followed by collection of the samples from the permeate and the retentate streams. By definition, the rejection of a solute is the relative concentration decrease between the two sides of the membrane (eqn (1)):

$$
R_{\mathrm{i}}=100 \% \cdot\left(1-\frac{C_{\mathrm{P}, \mathrm{i}}}{C_{\mathrm{R}, \mathrm{i}}}\right)
$$

where $R_{\mathrm{i}}$ is the rejection of the solute in percentage, $C_{\mathrm{R}, \mathrm{i}}$ and $C_{\mathrm{P}, \mathrm{i}}$ are the concentrations of the solute in the retentate and permeate, respectively, usually given in $\mathrm{g} \mathrm{L}^{-1}$. Flux is defined as the volume of solvent that permeates the membrane per unit area in a given time (eqn (2)):

$$
F=\frac{V_{\mathrm{P}}}{A t}
$$

where $F$ is the solvent flux, $V_{\mathrm{P}}$ is the permeate volume, $A$ is the membrane area and $t$ is the time of permeation. Diafiltration was carried out by collecting the permeate separately and keeping the retentate volume constant.

\section{Experimental - preparation of organocatalysts and aza-Markovnikov reactions}

General. Infrared spectra were recorded on a Bruker Alpha-T FT-IR spectrometer. Optical rotations were measured on a Perkin-Elmer 241 polarimeter. NMR spectra were recorded in $\mathrm{CDCl}_{3}$ on a Bruker DRX-500 Avance spectrometer (at 300 or $500 \mathrm{MHz}$ for ${ }^{1} \mathrm{H}$ and at 75.5 or $125 \mathrm{MHz}$ for ${ }^{13} \mathrm{C}$ spectra). LC-MS was performed on an HPLC system using Gemini RP C18 column $\left(150 \times 4.6 \mathrm{~mm}, 3 \mu \mathrm{m}, 256 \mathrm{~nm}, 40{ }^{\circ} \mathrm{C}, 0.6 \mathrm{~mL} \mathrm{~min}{ }^{-1}\right.$, gradient elution: water $\left(0.1 \% \mathrm{NH}_{4} \mathrm{HCO}_{3}\right)$ - acetonitrile $(0.1 \%$ $\mathrm{NH}_{4} \mathrm{HCO}_{3}+8 \%$ water)) in ESI mode. Enantioselectivities were determined by chiral HPLC using a Chiralpak column $(256 \mathrm{~nm}$, $20{ }^{\circ} \mathrm{C}, 2.0 \mathrm{~mL} \mathrm{~min}{ }^{-1}$, hexane : isopropyl alcohol $=4: 1$ ).

Voltage: $1.10 \mathrm{kV}, \mathrm{m} / \mathrm{z}: 105-1000$, scan speed: $1075 \mathrm{u} \mathrm{s}^{-1}$, DL temperature: $250{ }^{\circ} \mathrm{C}$, Nebulizing gas flow: $1.5 \mathrm{~L} \mathrm{~min}^{-1}$, drying gas.

Flow: $15 \mathrm{~L} \mathrm{~min}{ }^{-1}$. eluent: acetonitrile: $0.1 \mathrm{v} / \mathrm{v} \%$ formic acid $\left(95: 5,1.500 \mathrm{~mL} \mathrm{~min}^{-1}\right)$. Elemental analyses were performed on a Vario EL III instrument (Element analyze Corp., Germany) in the Microanalytical Laboratory of the Department of Organic Chemistry, Institute for Chemistry, L. Eötvös University, Budapest, Hungary. The starting materials were purchased from Aldrich Chemical Company unless otherwise noted. Silica gel $60 \mathrm{~F}_{254}$ (Merck) plates were used for TLC. Silica gel 60 (70-230 mesh, Merck) was used for column chromatography. The ratios of solvents for the eluents are given in volumes $(\mathrm{mL} / \mathrm{mL})$. Evaporations were carried out under reduced pressure unless otherwise stated. The cinchona-based organocatalysts ( 7 and 8 ) were synthesized based on the experiments of Bae and co-workers. ${ }^{25}$

General procedure for aza-Markovnikov additions. Vinyl ester $(0.72 \mathrm{mmol}, 1.2 \mathrm{eq}$.) was added to a solution of a catalyst $(0.03 \mathrm{mmol}, 0.05$ eq.) and an $\mathrm{N}$-heterocycle $(0.6 \mathrm{mmol})$ in a solvent $(1.2 \mathrm{~mL}$, see Table 1$)$. The reaction mixture was stirred at room temperature while being monitored by TLC. After two days, the solvent was removed. The crude product was purified by preparative thin layer chromatography on silica gel to obtain the aza-Markovnikov adduct as a pale yellow oil (yields can be seen in Tables 1, 3 and 4).

1-(1H-Imidazol-1-yl)ethyl acetate (4). Aza-Markovnikov adduct 4 was prepared as described in the general procedure starting from vinyl acetate $(3,66 \mu \mathrm{L}, 62 \mathrm{mg}, 0.72 \mathrm{mmol}, 1.2 \mathrm{eq}$.), imidazole $(1,40.8 \mathrm{mg}, 0.6 \mathrm{mmol})$ and the catalyst $\left(\mathrm{K}_{3} \mathrm{PO}_{4}\right.$ or 6 or 7 , $0.03 \mathrm{mmol}, 0.05$ eq.) in different solvents $(1.2 \mathrm{~mL}$ ) (see Table 1 ). The crude product was purified by preparative thin layer chromatography on silica gel using a dichloromethane:methanol $(10: 1)$ mixture as an eluent to give aza-Markovnikov adduct $\mathbf{4}$ as a pale yellow oil (yields can be seen in Tables 1, 3 and 4). Product 4 so obtained had the same spectroscopic data as those reported. ${ }^{38}$

1-(1H-Benzo[d]imidazol-1-yl)ethyl acetate (5). Aza-Markovnikov adduct 5 was prepared as described above in the general procedure starting from vinyl acetate $(3,66 \mu \mathrm{L}, 62 \mathrm{mg}, 0.72 \mathrm{mmol}, 1.2 \mathrm{eq}$.), benzimidazole $(2,70.9 \mathrm{mg}, 0.6 \mathrm{mmol})$ and the catalyst $\left(\mathrm{K}_{3} \mathrm{PO}_{4}\right.$ or 6 or 7 or $8,0.03 \mathrm{mmol}, 0.05$ eq.) in different solvents $(1.2 \mathrm{~mL}$, see Table 1 ). The crude product was purified by preparative thin layer chromatography on silica gel using a dichloromethane: methanol $(10: 1)$ mixture as an eluent to give aza-Markovnikov adduct $\mathbf{5}$ as a pale yellow oil (yields can be seen in Tables 1, 3 and 4). Product 5 so obtained had the same spectroscopic data as those reported. ${ }^{38}$

1-(1H-Pyrazol-1-yl)ethyl acetate (12). Aza-Markovnikov adduct 12 was prepared as described above in the general procedure starting from vinyl acetate $(3,66 \mu \mathrm{L}, 62 \mathrm{mg}, 0.72 \mathrm{mmol}, 1.2 \mathrm{eq}$.$) ,$ pyrazole $(9,40.8 \mathrm{mg}, 0.6 \mathrm{mmol})$ and the catalyst $\left(\mathrm{K}_{3} \mathrm{PO}_{4}\right.$ or 6 or 7 , $0.03 \mathrm{mmol}, 0.05$ eq.) in acetonitrile $(1.2 \mathrm{~mL})$. The crude product was purified by preparative thin layer chromatography on silica gel using a dichloromethane: methanol $(20: 1)$ mixture as an eluent to give aza-Markovnikov adduct $\mathbf{1 2}$ as a pale yellow oil (yields can be seen in Table 3). Product 12 so obtained had the same spectroscopic data as those reported. ${ }^{38}$

1-(1H-1,2,3-Triazol-1-yl)ethyl acetate (13) and 1-(1H-1,2,3triazol-2-yl)ethyl acetate (14). Aza-Markovnikov adducts 13 and $\mathbf{1 4}$ were prepared as described above in the general procedure starting from vinyl acetate $(3,66 \mu \mathrm{L}, 62 \mathrm{mg}, 0.72 \mathrm{mmol}, 1.2 \mathrm{eq}$.), 1,2,3-triazole $(\mathbf{1 0}, 41.4 \mathrm{mg}, 0.6 \mathrm{mmol})$ and the catalyst $\left(\mathrm{K}_{3} \mathrm{PO}_{4}\right.$ or 6 or $7,0.03 \mathrm{mmol}, 0.05$ eq.) in acetonitrile $(1.2 \mathrm{~mL})$. The crude product was purified by preparative thin layer chromatography 
on silica gel using a hexane : ethyl acetate $(1: 1)$ mixture as an eluent to give aza-Markovnikov adduct $\mathbf{1 3}$ and $\mathbf{1 4}$ as pale yellow oils (yields can be seen in Table 3$)$. TLC ( $\mathrm{SiO}_{2}$ TLC; hexane: ethyl acetate $=1: 1, R_{\mathrm{f}}=0.62$, UV).

1-(1H-1,2,3-Triazol-1-yl)ethyl acetate (13). IR (neat) $\nu_{\mathrm{max}} / \mathrm{cm}^{-1}$ 3132, $3002(\mathrm{C}=\mathrm{CH}), 2946(\mathrm{CH}), 2094,1751(\mathrm{C}=\mathrm{O}), 1485,1444$, $1371,1301,1284,1220,1196,1071 . \delta \mathrm{H}\left(500 \mathrm{MHz} ; \mathrm{CDCl}_{3} ; \mathrm{Me}_{4} \mathrm{Si}\right)$ $1.96\left(3 \mathrm{H}, \mathrm{d},{ }^{3} \mathrm{~J}_{\mathrm{H}, \mathrm{H}}=6.5 \mathrm{~Hz}, \mathrm{CCH}_{3}\right), 2.08\left(3 \mathrm{H}, \mathrm{s}, \mathrm{CH}_{3}\right), 7.06(1 \mathrm{H}, \mathrm{q}$, $\left.J_{\mathrm{H}, \mathrm{H}} 6.5, \mathrm{~N}-\mathrm{CH}-\mathrm{O}\right), 7.71[1 \mathrm{H}, \mathrm{s}, \operatorname{TriazC}(5)-\mathrm{H}], 7.79[1 \mathrm{H}, \mathrm{s}$, TriazC(4)-H]; $\delta \mathrm{C}\left(75.5 \mathrm{MHz} ; \mathrm{CDCl}_{3} ; \mathrm{Me}_{4} \mathrm{Si}\right) 19.64\left(\mathrm{CH}-\mathrm{CH}_{3}\right.$ group), $20.79\left(\mathrm{CH}_{3}\right), \quad 77.64(\mathrm{~N}-\mathrm{CH}-\mathrm{O}), 123.43 \quad$ [TriazC(5)], 133.73 [TriazC(4)], 169.39 (COO); MS (ESI): exact mass calcd for $\mathrm{C}_{6} \mathrm{H}_{9} \mathrm{~N}_{3} \mathrm{O}_{2}:$ 155.16. Found $m / z$ 156.200 $\left(\mathrm{M}^{+}, 56.47 \%\right)$. Anal. calcd for $\mathrm{C}_{6} \mathrm{H}_{9} \mathrm{~N}_{3} \mathrm{O}_{2}$ : C, 46.45; H, 5.85; N, 27.08. Found: C, 46.26; H, $5.94 ; \mathrm{N}, 27.07$.

1-(1H-1,2,3-Triazol-2-yl)ethyl acetate (14). IR (neat) $\nu_{\max } / \mathrm{cm}^{-1}$ 3124, $3001(\mathrm{C}=\mathrm{CH}), 2945(\mathrm{CH}), 1745(\mathrm{C}=\mathrm{O}), 1447,1414,1370$, 1344, 1214, 1117, 1079, 1064. $\delta \mathrm{H}\left(300 \mathrm{MHz} ; \mathrm{CDCl}_{3} ; \mathrm{Me}_{4} \mathrm{Si}\right) 1.93$ $\left(3 \mathrm{H}, \mathrm{d}, J_{\mathrm{H}, \mathrm{H}} 6.5, \mathrm{CCH}_{3}\right), 2.09\left(3 \mathrm{H}, \mathrm{s}, \mathrm{CH}_{3}\right), 7.15\left(1 \mathrm{H}, \mathrm{q}, J_{\mathrm{H}, \mathrm{H}} 6.0\right.$, $\mathrm{N}-\mathrm{CH}-\mathrm{O}), 7.70\left[2 \mathrm{H}, \mathrm{s}\right.$, TriazC-H]; $\delta \mathrm{C}\left(75.5 \mathrm{MHz} ; \mathrm{CDCl}_{3} ; \mathrm{Me}_{4} \mathrm{Si}\right)$ $19.28\left(\mathrm{CH}-\mathrm{CH}_{3}\right.$ group), $20.84\left(\mathrm{CH}_{3}\right), 81.25(\mathrm{~N}-\mathrm{CH}-\mathrm{O}), 135.17$ [TriazC], 169.12 (COO); MS (ESI): exact mass calcd for $\mathrm{C}_{6} \mathrm{H}_{9} \mathrm{~N}_{3} \mathrm{O}_{2}: 155.16$, found $m / z 156.132\left(\mathrm{M}^{+}, 44.78 \%\right)$. Anal. calcd for $\mathrm{C}_{6} \mathrm{H}_{9} \mathrm{~N}_{3} \mathrm{O}_{2}$ : C, 46.45; $\mathrm{H}, 5.85 ; \mathrm{N}, 27.08$. Found: C, 46.26; H, $5.94 ; \mathrm{N}, 27.07$.

1-(1H-Imidazol-1-yl)ethyl 4-(tert-butyl)benzoate (15). AzaMarkovnikov adduct 15 was prepared as described above in the general procedure starting from vinyl 4-(tert-butyl)benzoate (11, $147 \mu \mathrm{L}, 147.1 \mathrm{mg}, 0.72 \mathrm{mmol}, 1.2 \mathrm{eq}$.), imidazole (1, $40.8 \mathrm{mg}$, $0.6 \mathrm{mmol})$ and the catalyst $\left(\mathrm{K}_{3} \mathrm{PO}_{4}\right.$ or 6 or $7,0.03 \mathrm{mmol}, 0.05$ eq. in acetonitrile $(1.2 \mathrm{~mL})$. The crude product was purified by preparative thin layer chromatography on silica gel using a dichloromethane: methanol (20:1) mixture as an eluent to give aza-Markovnikov adduct $\mathbf{1 5}$ as a pale yellow oil (yields can be seen in Table 3). TLC $\left(\mathrm{SiO}_{2} \mathrm{TLC}\right.$; dichloromethane: methanol = 20:1, $\left.R_{\mathrm{f}}=0.48, \mathrm{UV}\right)$. IR (neat) $\nu_{\max } / \mathrm{cm}^{-1} 3115,2963(\mathrm{CH}), 2905(\mathrm{CH})$, $2869(\mathrm{CH}), 1718(\mathrm{C}=\mathrm{O}), 1608(\mathrm{C}=\mathrm{C}), 1493,1261,1223,1188$, 1071, 1033, 1014. $\delta \mathrm{H}\left(500 \mathrm{MHz} ; \mathrm{CDCl}_{3} ; \mathrm{Me}_{4} \mathrm{Si}\right) 1.35$ (9 H, s, $t \mathrm{Bu}$ $\mathrm{CH}_{3}$ groups), $1.95\left(3 \mathrm{H}, \mathrm{d}, J_{\mathrm{H}, \mathrm{H}} 6.5, \mathrm{CCH}_{3}\right), 6.99\left(1 \mathrm{H}, \mathrm{q}, J_{\mathrm{H}, \mathrm{H}} 6.0\right.$, $\mathrm{N}-\mathrm{CH}-\mathrm{O}), 7.10$ [1 H, s, ImC(4)-H], 7.29 [1 H, s, ImC(5)-H], 7.48 and $7.95\left(2 \times 2 \mathrm{H}, \mathrm{AA}^{\prime} \mathrm{BB}^{\prime}, J_{\mathrm{AB}} 8.5, \mathrm{Ph}-\mathrm{H}\right), 7.85$ [s, $\left.1 \mathrm{H}, \operatorname{ImC}(2)-\mathrm{H}\right]$; $\delta \mathrm{C}\left(125 \mathrm{MHz} ; \mathrm{CDCl}_{3} ; \mathrm{Me}_{4} \mathrm{Si}\right) 20.44\left(\mathrm{CH}-\mathrm{CH}_{3}\right.$ group), $31.06(t \mathrm{Bu}$ $\mathrm{CH}_{3}$ groups), 35.18 ( $\left.t \mathrm{Bu} \mathrm{C}-\mathrm{CH}_{3}\right), 75.63(\mathrm{~N}-\mathrm{CH}-\mathrm{O}), 116.85$ $[\operatorname{ImC}(5)], 125.53[\mathrm{PhC}(3)], 126.08[\mathrm{PhC}(1)], 129.68[\operatorname{ImC}(4)]$, 129.74 [PhC(2)], 136.50 [ImC(2)], 157.61 [PhC(4)], 165.04 (COO); MS (ESI): exact mass calcd for $\mathrm{C}_{16} \mathrm{H}_{20} \mathrm{~N}_{2} \mathrm{O}_{2}: 272.15$, found $\mathrm{m} / \mathrm{z}$ $273.200\left(\mathrm{M}^{+}, 100 \%\right)$. Anal. calcd for $\mathrm{C}_{16} \mathrm{H}_{20} \mathrm{~N}_{2} \mathrm{O}_{2}$ : C, 70.56; H, 7.40; N, 10.29. Found: C, 70.48; H, 7.59; N, 10.19.

1-(1H-Benzo[d]imidazol-1-yl)ethyl 4-(tert-butyl)benzoate (16). Aza-Markovnikov adduct $\mathbf{1 6}$ was prepared as described above in the general procedure starting from vinyl 4-(tert-butyl)benzoate (11, $147 \mu \mathrm{L}, 147.1 \mathrm{mg}, 0.72 \mathrm{mmol}, 1.2 \mathrm{eq}$.), benzimidazole (2, $70.9 \mathrm{mg}$, $0.6 \mathrm{mmol})$ and the catalyst $\left(\mathrm{K}_{3} \mathrm{PO}_{4}\right.$ or 6 or $7,0.03 \mathrm{mmol}, 0.05$ eq. in acetonitrile $(1.2 \mathrm{~mL})$. The crude product was purified by preparative thin layer chromatography on silica gel using a dichloromethane: methanol $(20: 1)$ mixture as an eluent to give
aza-Markovnikov adduct $\mathbf{1 6}$ as a pale yellow oil (yields can be seen in Table 4). TLC $\left(\mathrm{SiO}_{2} \mathrm{TLC}\right.$; dichloromethane : methanol $=20: 1$, $\left.R_{\mathrm{f}}=0.68, \mathrm{UV}\right)$. IR (neat) $\nu_{\max } / \mathrm{cm}^{-1} 3058(\mathrm{C}=\mathrm{CH}), 2997(\mathrm{C}=\mathrm{CH})$, $2963(\mathrm{CH}), 2869,2748,2720,2684,1938,1726(\mathrm{C}=\mathrm{O}), 1609(\mathrm{C}=\mathrm{C})$, 1496, 1483, 1459, 1409, 1282, 1273, 1219, 1185, 1116, 1089, 1062 $\delta \mathrm{H}\left(500 \mathrm{MHz} ; \mathrm{CDCl}_{3} ; \mathrm{Me}_{4} \mathrm{Si}\right) 1.34\left(9 \mathrm{H}, \mathrm{s}, t \mathrm{Bu} \mathrm{CH}_{3}\right.$ groups), 2.11 (3 H, d, $\left.J_{\mathrm{H}, \mathrm{H}} 6.0, \mathrm{CCH}_{3}\right), 7.30-7.37\left[3 \mathrm{H}, \mathrm{m}, J_{\mathrm{H}, \mathrm{H}} 6.0, \mathrm{~N}-\mathrm{CH}-\mathrm{O}\right.$, $\operatorname{BimC}(5)-\mathrm{H}, \operatorname{BimC}(6)-\mathrm{H}], 7.46$ and $7.96\left(2 \times 2 \mathrm{H}, \mathrm{AA}^{\prime} \mathrm{BB}^{\prime}, J_{\mathrm{AB}} 8.5\right.$, $\mathrm{Ph}-\mathrm{H}), 7.70\left[1 \mathrm{H}, \mathrm{d}, J_{\mathrm{H}, \mathrm{H}}\right.$ 8.0, $\operatorname{BimC}(4)-\mathrm{H}$ or $\left.\operatorname{BimC}(7)-\mathrm{H}\right], 7.84[1 \mathrm{H}$, $\mathrm{s}, J_{\mathrm{H}, \mathrm{H}} 7.5, \operatorname{BimC}(4)-\mathrm{H}$ or $\left.\operatorname{BimC}(7)-\mathrm{H}\right], 8.24$ [1 H, s, BimC(2)-H]; $\delta \mathrm{C}\left(125 \mathrm{MHz} ; \mathrm{CDCl}_{3} ; \mathrm{Me}_{4} \mathrm{Si}\right) 20.10\left(\mathrm{CH}-\mathrm{CH}_{3}\right.$ group), $31.05\left(t \mathrm{Bu} \mathrm{CH}_{3}\right.$ groups), $35.18\left(t \mathrm{Bu} \mathrm{C}-\mathrm{CH}_{3}\right), 75.43(\mathrm{~N}-\mathrm{CH}-\mathrm{O}), 110.98$ [BimC(7)], $120.62[\mathrm{BimC}(4)], 122.86[\operatorname{BimC}(5), \operatorname{BimC}(6)], 123.62[\operatorname{BimC}(5)$, $\operatorname{BimC}(6)], 125.55 \quad[\mathrm{PhC}(3)], 126.00 \quad[\mathrm{PhC}(1)], 129.77 \quad[\mathrm{PhC}(2)]$, 132.47 [Bim(8)], $141.13[\mathrm{Bim}(9)], 143.97[\mathrm{Bim}(2)], 157.62[\mathrm{PhC}(4)]$, 165.08 (COO); MS (ESI): exact mass calcd for $\mathrm{C}_{20} \mathrm{H}_{22} \mathrm{~N}_{2} \mathrm{O}_{2}$ : 322.17, found $m / z 323.200\left(\mathrm{M}^{+}, 100 \%\right)$. Anal. calcd for $\mathrm{C}_{20} \mathrm{H}_{22} \mathrm{~N}_{2} \mathrm{O}_{2}: \mathrm{C}$, 74.51; H, 6.88; N, 8.69. Found: C, 74.49; H, 6.90; N, 8.68.

1-(1H-Pyrazol-1-yl)ethyl 4-(tert-butyl)benzoate (17). AzaMarkovnikov adduct $\mathbf{1 7}$ was prepared as described above in the general procedure starting from vinyl 4-(tert-butyl)benzoate (11, $147 \mu \mathrm{L}, 147.1 \mathrm{mg}, 0.72 \mathrm{mmol}, 1.2 \mathrm{eq}$.), pyrazole (9, $40.8 \mathrm{mg}$, $0.6 \mathrm{mmol})$ and the catalyst $\left(\mathrm{K}_{3} \mathrm{PO}_{4}\right.$ or 6 or $7,0.03 \mathrm{mmol}, 0.05$ eq. in acetonitrile $(1.2 \mathrm{~mL})$. The crude product was purified by preparative thin layer chromatography on silica gel using a hexane: ethyl acetate $(4: 1)$ mixture as an eluent to give azaMarkovnikov adduct $\mathbf{1 7}$ as a pale yellow oil (yields can be seen in Table 3). TLC ( $\mathrm{SiO}_{2}$ TLC; hexane : ethyl acetate $=4: 1, R_{\mathrm{f}}=$ 0.41, UV). IR (neat) $\nu_{\max } / \mathrm{cm}^{-1} 3122,2964(\mathrm{CH}), 2906(\mathrm{CH}), 2870$ (CH), 2427, 2296, 2097, 1931, 1806, $1719(\mathrm{C}=\mathrm{O}), 1609(\mathrm{C}=\mathrm{C})$, 1519, 1441, 1398, 1256, 1188, 1113, 1089, 1066, 1041, 1014. $\delta \mathrm{H}\left(500 \mathrm{MHz} ; \mathrm{CDCl}_{3} ; \mathrm{Me}_{4} \mathrm{Si}\right) 1.34\left(9 \mathrm{H}, \mathrm{s}, t \mathrm{Bu} \mathrm{CH}_{3}\right.$ groups), 2.02 $\left(3 \mathrm{H}, \mathrm{d}, J_{\mathrm{H}, \mathrm{H}} 6.5, \mathrm{CCH}_{3}\right), 6.31\left[1 \mathrm{H}, \mathrm{t}, J_{\mathrm{H}, \mathrm{H}} 2.0, \operatorname{PyrC}(4)\right], 7.10(1 \mathrm{H}$, $\left.\mathrm{q}, J_{\mathrm{H}, \mathrm{H}} 6.0, \mathrm{~N}-\mathrm{CH}-\mathrm{O}\right), 7.45$ and $7.98\left(2 \times 2 \mathrm{H}, \mathrm{AA}^{\prime} \mathrm{BB}^{\prime}, J_{\mathrm{AB}} 8.5\right.$, Ph$\mathrm{H}), 7.62[1 \mathrm{H}, \mathrm{s}, \operatorname{PyrC}(3)-\mathrm{H}], 7.75\left[1 \mathrm{H}, \mathrm{d}, J_{\mathrm{H}, \mathrm{H}} 2.5\right.$, PyrC(5)-H]; $\delta \mathrm{C}\left(125 \mathrm{MHz} ; \mathrm{CDCl}_{3} ; \mathrm{Me}_{4} \mathrm{Si}\right) 19.42\left(\mathrm{CH}-\mathrm{CH}_{3}\right.$ group), $31.07(t \mathrm{Bu}$ $\mathrm{CH}_{3}$ groups), 35.13 ( $\left.t \mathrm{Bu} \mathrm{C}-\mathrm{CH}_{3}\right), 79.24$ (N-CH-O), 106.15 [PyrC(4)], $125.40[\mathrm{PhC}(3)], 126.46[\mathrm{PhC}(1)], 129.81$ [PhC(2)], 129.87 [PyrC(5)], 140.46 [PyrC(3)], 157.30 [PhC(4)], 165.35 (COO); MS (ESI): exact mass calcd for $\mathrm{C}_{16} \mathrm{H}_{20} \mathrm{~N}_{2} \mathrm{O}_{2}: 272.15$, found $m / z 273.200\left(\mathrm{M}^{+}, 100 \%\right)$. Anal. calcd for $\mathrm{C}_{16} \mathrm{H}_{20} \mathrm{~N}_{2} \mathrm{O}_{2}$ : C, 70.56; H, 7.40; N, 10.29. Found: C, 70.49; H, 7.45; N, 10.23.

1-(1H-Triazol-1-yl)ethyl 4-(tert-butyl)benzoate (18) and 1-(1Htriazol-2-yl)ethyl 4-(tert-butyl)benzoate (19). Aza-Markovnikov adducts 18 and 19 were prepared as described above in the general procedure starting from vinyl 4-(tert-butyl)benzoate (11, $147 \mu \mathrm{L}, 147.1 \mathrm{mg}, 0.72 \mathrm{mmol}, 1.2$ eq.), 1,2,3-triazole (10, $41.4 \mathrm{mg}, 0.6 \mathrm{mmol})$ and the catalyst $\left(\mathrm{K}_{3} \mathrm{PO}_{4}\right.$ or 6 or $7,0.03 \mathrm{mmol}$, 0.05 eq.) in acetonitrile $(1.2 \mathrm{~mL})$. The crude product was purified by preparative thin layer chromatography on silica gel using a hexane : ethyl acetate $(1: 1)$ mixture as an eluent to give aza-Markovnikov adducts 18 and 19 as pale yellow oils (yields can be seen in Table 3 ).

1-(1H-Triazol-1-yl)ethyl 4-(tert-butyl)benzoate (18). TLC ( $\mathrm{SiO}_{2} \mathrm{TLC}$; hexane : ethyl acetate $\left.=1: 1, R_{\mathrm{f}}=0.48, \mathrm{UV}\right) . \mathrm{IR}$ (neat) $\nu_{\max } / \mathrm{cm}^{-1} 3130$, $2963(\mathrm{CH}), 2870(\mathrm{CH}), 2389,2300,2096,1938,1719(\mathrm{C}=\mathrm{O})$, 
$1608(\mathrm{C}=\mathrm{C}), 1573,1460,1409,1365,1339,1262,1187,1078$, 1034, 1011. ${ }^{1} \mathrm{H}$ NMR $\left(500 \mathrm{MHz}, \mathrm{CDCl}_{3}\right): \delta(\mathrm{ppm}) 1.34(9 \mathrm{H}, \mathrm{s}, t \mathrm{Bu}$ $\mathrm{CH}_{3}$ groups), $2.13\left(3 \mathrm{H}, \mathrm{d}, J_{\mathrm{H}, \mathrm{H}} 6.5, \mathrm{CCH}_{3}\right), 7.32\left(1 \mathrm{H}, \mathrm{q}, J_{\mathrm{H}, \mathrm{H}} 6.5\right.$, $\mathrm{N}-\mathrm{CH}-\mathrm{O}), 7.48$ and $7.98\left(2 \times 2 \mathrm{H}, \mathrm{AA}^{\prime} \mathrm{BB}^{\prime}, J_{\mathrm{AB}} 8.5, \mathrm{Ph}-\mathrm{H}\right), 7.74[1 \mathrm{H}$, s, TriazC(5)-H], $7.90[1 \mathrm{H}, \mathrm{s}, \operatorname{TriazC}(4)-\mathrm{H}] ; \delta \mathrm{C}\left(125 \mathrm{MHz} ; \mathrm{CDCl}_{3}\right.$; $\left.\mathrm{Me}_{4} \mathrm{Si}\right) 19.69\left(\mathrm{CH}-\mathrm{CH}_{3}\right.$ group), 31.04 ( $t \mathrm{Bu} \mathrm{CH}_{3}$ groups), $35.20(t \mathrm{Bu}$ $\left.\mathrm{C}-\mathrm{CH}_{3}\right), 77.98$ (N-CH-O), 125.58 [PhC(3)], 123.63 [TriazC(3)], 126.19 [PhC(1)], 129.89 [PhC(2)], 135.15 [TriazC(4)], 157.86 [PhC(4)], 164.95 (COO); MS (ESI): exact mass calcd for $\mathrm{C}_{15} \mathrm{H}_{19} \mathrm{~N}_{3} \mathrm{O}_{2}$ : 273.15, found $m / z 274.100\left(\mathrm{M}^{+}, 177.43 \%\right)$. Anal. calcd for $\mathrm{C}_{15} \mathrm{H}_{19} \mathrm{~N}_{3} \mathrm{O}_{2}: \mathrm{C}, 65.91 ; \mathrm{H}$, 7.01; N, 15.37. Found: C, 65.82; H, 7.18; N, 15.35.

1-(1H-1,2,3-Triazol-2-yl)ethyl 4-(tert-butyl)benzoate (19). TLC $\left(\mathrm{SiO}_{2}\right.$ TLC; hexane $:$ ethyl acetate $=1: 1, R_{\mathrm{f}}=0.82$, UV). IR (neat) $\nu_{\max } / \mathrm{cm}^{-1}$ 3428, $2964(\mathrm{CH}), 2869(\mathrm{CH}), 2399,2281,2098,1939$, $1724(\mathrm{C}=\mathrm{O}), 1609(\mathrm{C}=\mathrm{C}), 1572,1463,1410,1365,1343,1267$, 1242, 1188, 1089, 1061, 1015. $\delta \mathrm{H}\left(500 \mathrm{MHz} ; \mathrm{CDCl}_{3} ; \mathrm{Me}_{4} \mathrm{Si}\right) 1.33$ (9 H, s, $t \mathrm{Bu} \mathrm{CH}_{3}$ groups), $2.06\left(3 \mathrm{H}, \mathrm{d}, J_{\mathrm{H}, \mathrm{H}} 6.5, \mathrm{CCH}_{3}\right), 7.42-7.44$ [1 H, m, N-CH-O], 7.44 and $7.98\left(2 \times 2 \mathrm{H}, \mathrm{AA}^{\prime} \mathrm{BB}^{\prime}, J_{\mathrm{AB}} 8.5, \mathrm{Ph}-\mathrm{H}\right)$, $7.72[2 \mathrm{H}, \mathrm{s}, \operatorname{TriazC}(4)-\mathrm{H}, \operatorname{TriazC}(5)-\mathrm{H}] ; \delta \mathrm{C}\left(125 \mathrm{MHz} ; \mathrm{CDCl}_{3}\right.$; $\left.\mathrm{Me}_{4} \mathrm{Si}\right) 19.38$ ( $\mathrm{CH}-\mathrm{CH}_{3}$ group), $31.06\left(t \mathrm{Bu} \mathrm{CH}_{3}\right.$ groups), 35.14 $\left(t \mathrm{Bu} \mathrm{C}-\mathrm{CH}_{3}\right), 81.46(\mathrm{~N}-\mathrm{CH}-\mathrm{O}), 125.42[\mathrm{PhC}(3)], 126.19$ [PhC(1)], $129.90[\mathrm{PhC}(2)], 135.15[\operatorname{TriazC}(4), \operatorname{TriazC}(5)], 157.38[\mathrm{PhC}(4)]$, 164.67 (COO); $\mathrm{MS}$ (ESI): exact mass calcd for $\mathrm{C}_{15} \mathrm{H}_{19} \mathrm{~N}_{3} \mathrm{O}_{2}$ : 273.15, found $m / z 274.200\left(\mathrm{M}^{+}, 91.42 \%\right)$. Anal. calcd for $\mathrm{C}_{15} \mathrm{H}_{19} \mathrm{~N}_{3} \mathrm{O}_{2}$ : C, 65.91; H, 7.01; N, 15.37. Found: C, 65.79; H, 7.20; N, 15.34.

\section{Conflicts of interest}

There are no conflicts to declare.

\section{Acknowledgements}

Financial support from the National Research, Development and Innovation office (former OTKA, grant number K112289), the Servier-Beregi PhD Research Fellowship and the New Széchenyi Development Plan (TÁMOP_4.2.1/B-09/1/KMR-2010-0002) is gratefully acknowledged.

\section{Notes and references}

1 S. France, D. J. Guerin, S. J. Miller and T. Lectka, Chem. Rev., 2003, 103, 2985.

2 K. Kacprzak and J. Gawronski, Synthesis, 2001, 961.

3 T. Marcelli and H. Hiemstra, Synthesis, 2010, 1229.

4 E. M. O. Yeboah, S. O. Yeboah and G. S. Singh, Tetrahedron, 2011, 67, 1725.

5 M. North, Sustainable Catalysis: Without Metals or Other Endangered Elements, Part 2, 2016.

6 C. E. Song, Cinchona Alkaloids in Synthesis and Catalysis: Ligands, Immobilization and Organocatalysis, Weinheim, 2009.

7 G. Tanriver, B. Dedeoglu, S. Catak and V. Aviyente, Acc. Chem. Res., 2016, 49, 1250.

8 D. Susam and C. Tanyeli, New J. Chem., 2017, 41, 3555.

9 T. Penaska, K. Ormandyova, M. Meciarova, J. Filo and R. Sebesta, New J. Chem., 2017, 41, 5506.
10 S. Karahan and C. Tanyeli, New J. Chem., 2017, 41, 9192.

11 S. W. Lin, Q. Sun, R. T. Li, T. M. Cheng and Z. M. Ge, Synthesis, 2007, 1933.

12 T. Yano, H. Tomioka, T. Ishiwatari and N. Hirata, Chem. Abstr., 1992, 116.

13 T. Yano; H. Tomioka; T. Ishiwatari and N. Hirata, JP03232805, 1991.

14 S. Ozaki, Y. Watanabe, T. Hoshiko, H. Mizuno, K. Ishikawa and H. Mori, Chem. Pharm. Bull., 1984, 32, 733.

15 J. C. Sih, W. B. Im, A. Robert, D. R. Graber and D. P. Blakeman, J. Med. Chem., 1991, 34, 1049.

16 W. B. Wu, N. Wang, J. M. Xu, Q. Wu and X. F. Lin, Chem. Commun., 2005, 2348.

17 W. B. Wu, J. M. Xu, Q. Wu, D. S. Lv and X. F. Lin, Adv. Synth. Catal., 2006, 348, 487.

18 X. W. Chen, X. H. Li, H. B. Song, Y. Qian and F. R. Wang, Tetrahedron Lett., 2011, 52, 3588.

19 G. Szekely, M. F. Jimenez-Solomon, P. Marchetti, J. F. Kim and A. G. Livingston, Green Chem., 2014, 16, 4440.

20 J. F. Kim, G. Szekely, M. Schaepertoens, I. B. Valtcheva, M. F. Jimenez-Solomon and A. G. Livingston, ACS Sustainable Chem. Eng., 2014, 2, 2371.

21 G. Szekely, I. B. Valtcheva, J. F. Kim and A. G. Livingston, React. Funct. Polym., 2015, 86, 215.

22 L. Peeva, J. D. Burgal, S. Vartak and A. G. Livingston, J. Catal., 2013, 306, 190.

23 W. E. Siew, C. Ates, A. Merschaert and A. G. Livingston, Green Chem., 2013, 15, 663.

24 R. A. Sheldon, Green Chem., 2007, 9, 1273.

25 R. A. Sheldon, Chem. Commun., 2008, 3352.

26 C. M. Alder, J. D. Hayler, R. K. Henderson, A. M. Redman, L. Shukla, L. E. Shuster and H. F. Sneddon, Green Chem., 2016, 18, 3879.

27 D. Prat, J. Hayler and A. Wells, Green Chem., 2014, 16, 4546.

28 T. Welton, Proc. R. Soc. London, Ser. A, 2015, 471, 1.

29 F. P. Byrne, S. Jin, G. Paggiola, T. H. M. Petchey, J. H. Clark, T. J. Farmer, A. J. Hunt, C. Robert McElroy and J. Sherwood, Sustainable Chem. Processes, 2016, 4, 7.

30 M. Kidwai, N. K. Mishra and A. Jahan, Chin. Chem. Lett., 2011, 22, 417.

31 H. Y. Bae, S. Some, J. H. Lee, J. Y. Kim, M. J. Song, S. Lee, Y. J. Zhang and C. E. Song, Adv. Synth. Catal., 2011, 353, 3196.

32 A. Moran, A. Hamilton, C. Bo and P. Melchiorre, J. Am. Chem. Soc., 2013, 135, 9091.

33 P. Melchiorre, M. Marigo, A. Carlone and G. Bartoli, Angew. Chem., Int. Ed., 2008, 47, 6138.

34 J. F. Kim, G. Szekely, I. B. Valtcheva and A. G. Livingston, Green Chem., 2014, 16, 133.

35 C. Didaskalou, S. Buyuktiryaki, R. Kecili, C. P. Fonte and G. Szekely, Green Chem., 2017, 19, 3116.

36 M. Schaepertoens, C. Didaskalou, J. F. Kim, A. G. Livingston and G. Szekely, J. Membr. Sci., 2016, 514, 646.

37 M. Razali, C. Didaskalou, J. F. Kim, M. Babaei, E. Drioli, Y. M. Lee and G. Szekely, ACS Appl. Mater. Interfaces, 2017, 9, 11279.

38 M. Kidwai, M. Lal, N. K. Mishra and A. Jahan, Green Chem. Lett. Rev., 2013, 6, 63. 